\title{
How Strategy and Industry Should Shape Your Choice of Co- Founders
}

\author{
Charles Eesley (Stanford University) \\ Edward Roberts (Massachusetts Institute of Technology) \\ David Hsu (University of Pennsylvania)
}

KEYWORDS: Entrepreneurship, Innovation, Strategy, Technology Commercialization, Startups.

Entrepreneurs who want to turn a great idea into a thriving business inevitably need a team that can make it happen. What increases their odds of a successful venture: hiring mainly technical experts to develop and perfect the product or service, or a full array of specialties - including operating, marketing and strategy experts - from the very beginning?

Using data collected from a survey of 2,007 firms, we studied this question in depth. We found out that the answer depends on two things: the competitiveness of the market in which the startup operates, and whether the startup can be considered an innovator.

We determined that founding teams that have diverse skills and specialties enjoy a high probability of success when they face competition in getting their product or service to market. Conversely, we found that founding teams comprised largely of technical experts are better suited to perform well if they are focused on innovating and if they are operating in a business environment that is cooperative (in the sense that incumbents and startups tend to partner).

The question of what makes a venture successful has been extensively studied for decades. Previous studies concluded that the composition of top management teams (TMTs) tends to be more uniform in nature, which translates into speedier execution (Brown and Eisenhardt, 1997; Eisenhardt and Schoonhoven, 1990). On the other hand, more diverse TMTs provide for more access to a broader range of skills, and overall, such teams tend to be more successful.

However, one aspect that had not been well researched is the relationship between a founding team's composition and the venture's business environment and strategy with respect to the endeavor's future performance. Our research indicates that one type of management team is not uniformly better than the other, but rather that the relationship between founding team composition and performance depends on the business environment and business strategy.

Because of the stark difference in strengths and weaknesses between the two team compositions, we guessed that different team types would thrive in different conditions.

\section{Our Research}

Our field study looked at more than 2,000 ventures started by Massachusetts Institute of Technology alumni and analyzed three central variables. First, we split founding teams into two categories: those that could be considered a diverse team-teams with founders whose skills broadly ranged from four different categories of technology, finance, sales and marketing, or other-or a technically focused team-more uniform teams comprised solely of founders whose roles primarily focused on technical skills in science and engineering.

Second, we looked at the type of business environment that the venture competes in. The two types of environments which we tested were competitive commercialization or cooperative commercialization. In the first type, companies have little to no motivation to work with third parties. They face similar barriers, such as limited protection of intellectual property, difficulties retaining innovation ideas, and relatively low costs of assets necessary for market entry. In contrast, in cooperative commercialization environments, companies benefit from partnering with industry incumbents. They are in industries where the assets owned by incumbents are difficult to replicate, where 
they typically are better able to protect their technology through secrecy or patent protection, or where high barriers to entry limit competition.

Lastly, we accounted for the importance of innovation within the company's business strategy. For this, we created a three-point scale in which companies were categorized by their reliance on innovation, based on whether they held patents and if they were affiliated with any third-party labs such as universities or corporate research labs. The impact of founding team composition turns out to depend on whether the firm is an innovator or not.

\section{The Findings}

We analyzed how these three variables affected a firm's success, defined as whether their founders and equity holders reaped financial rewards through an IPO or merger. We saw that ultimately this interplay between business environment and innovation strategy was found to be a crucial element in determining the most effective team composition. Technically focused founding teams achieve the best results if they operate in an industry with cooperative commercialization and choose to be innovators, developing new-to-the-world products and services. Diverse TMTs, however, had better results in competitive commercialization environments.

In summary, it was previously thought that functionally diverse founding teams held an overall advantage when examined through the lens of factors such as the company's business strategy and market growth. Our research shows that diverse teams are optimally suited for particular environments (competitive commercialization) while uniform technically focused teams focused on innovating are better suited for a cooperative commercialization environment. It was also believed that there is a new venture "life cycle" in which new managers are brought in with appropriate skills at various stages as the firm matures, thus perhaps mitigating the effects of not having an optimal founding team. An important offshoot of our work is that it demonstrates that it may be very important to have the ideal founding team from the very outset in order to maximize the chances of a firm's eventual success. This implication is due to the fact that we find significant effects for the initial founding team. If it were easy to add top executives or employees subsequently to make up for deficiencies in the founding team composition, then we would not expect to see such strong effects of the initial founding team characteristics.

\section{The Takeaway}

- Entrepreneurs facing lots of competition to get a product to market should consider a team where all kinds of disciplines are represented. This will give them the expertise they need to anticipate and handle all types of competitive challenges.

- If your company faces little to no marketplace competition, it can afford to partner with other firms to get a product to market. You can use patents and other legal strategies to protect your intellectual property.

- If you are an "innovator firm" developing totally new ideas or products, diverse teams don't confer as much benefit. You will likely enjoy greater success with a technically focused team that can tap into a close network of talent, work constructively with universities and focus more brainpower to developing and perfecting the product.

\section{References}

Research Translation of Eesley, C.E.; Hsu, D.; Roberts, E.B. 2014. The Contingent Effects of Top Management Teams on Venture Performance (http://onlinelibrary.wiley.com/doi/10.1002/smj.2183/abs tract) : Aligning Founding Team Composition with Innovation Strategy and Commercialization Environment. Strategic Management Journal, Volume 35, Issue 12, pp. 1798-1817. 